(1)

CrossMark

\title{
Inhaled corticosteroids and pneumonia mortality in COPD patients
}

\author{
To the Editor:
}

In a recent article, SUISSA [1] proposes several alternative hypotheses to explain the paradoxical effect of inhaled corticosteroids (ICS) in chronic obstructive pulmonary disease (COPD) patients, whereby these drugs can increase the risk of pneumonia and simultaneously reduce pneumonia mortality. In our opinion, the conclusion of the article, that pneumonia mortality is increased in COPD patients treated with ICS, both in observational and in randomised clinical trials (RCTs), is not supported by data and cannot be considered confirmed. Basically, the author maintains that this paradox can be explained by the small number of events in randomised clinical trials (RCTs) and selection bias in observational studies [1].

First, pneumonia risk is increased in patients with COPD, and chronic treatment with ICS further increases this risk $[2,3]$. However, this higher incidence of pneumonia is not uniform in different studies, and in recent RCTs conducted in a large number of patients the incidence of pneumonia was not increased in patients randomised to ICS treatment [4-6]. This suggests that other factors, such as the specific drug, dose and population studied, may affect this risk.

SuISSA [1] suggests that ICS-treated patients may develop pneumonia for the same reasons as the rest of COPD patients, and additionally due to factors directly attributable to ICS. Two different concepts used by the author should be clarified: 1) pneumonia mortality (pneumonia deaths/total number of patients), and 2) case fatality (pneumonia deaths/number of patients with pneumonia). Following the same example used in the article, if the risk of pneumonia in ICS users is 2, and the prognosis of severe cases of pneumonia (case fatality) is similar for ICS and non-ICS users, global mortality for pneumonia in ICS users should be 2 . Conversely, if pneumonia mortality is similar, the prognosis of severe cases of pneumonia should be 0.5 . In our opinion, this option is more realistic since in the meta-analysis conducted by FESTIC et al. [3] case fatality in observational studies was lower in ICS users (RR 0.7, 95\% CI 0.59-0.88).

Secondly, SuISSA [1] proposes that the lower mortality for pneumonia observed in these studies can be explained by selection bias. The argument is that this lower mortality in ICS patients may be related to fewer comorbidities or having less severe COPD, among other factors. However, observational studies statistically adjust for many of these possible confounders, and we cannot find any plausible reason to explain why patients not treated with ICS should have more comorbidities or more severe COPD than ICS-treated patients [7].

To avoid this bias SuISSA [1] analysed a cohort study defined by ICS exposure at inclusion. In this study, performed between 1998 and 2003, pneumonia mortality was increased in ICS patients. However, global mortality was lower with ICS use, which can lead to a bias (only living patients can die of pneumonia). In subsequent publications, S. Suissa and co-workers confirm that ICS patients had an increased risk of severe pneumonias, but regrettably, the authors did not explore the mortality data in these studies $[8,9]$.

Finally, the meta-analysis of RCTs referenced in the article showed an increase in pneumonia mortality among patients treated with ICS, though this relationship did not reach statistical significance (RR 1.50, 95\% CI 0.85-2.67), and the authors concluded that the risk of pneumonia mortality was not increased in ICS users [3]. SuISSA [1] suggests that the reason is the limited number of events. This may be a factor, but the total number of patients included in this meta-analysis is considerable (12958 patients). Of note, since the publication of this meta-analysis, at least 10 RCTs containing 40424 COPD patients randomised to ICS treatment have been published (table 1). Of these, in seven (24811 patients) non-fatal pneumonia

@ERSpublications

Chronic use of ICS increases the risk of pneumonia in COPD patients, although this risk is not homogenous. This study confirms that the risk of pneumonia-related mortality in randomised clinical trials is not increased in patients treated with ICS. http://bit.ly/2Zod6us

Cite this article as: Almagro P, Martinez-Camblor P, Soriano JB. Inhaled corticosteroids and pneumonia mortality in COPD patients. Eur Respir J 2019; 54: 1901035 [https://doi.org/10.1183/13993003.010352019]. 


\begin{tabular}{|c|c|c|c|c|c|c|}
\hline \multirow[t]{2}{*}{ Studies } & \multirow[t]{2}{*}{ Drug } & \multicolumn{3}{|c|}{ Patients } & \multicolumn{2}{|c|}{$\begin{array}{c}\text { Pneumonia } \\
\text { mortality }\end{array}$} \\
\hline & & Total & ICS & Non-ICS & ICS & Non-ICS \\
\hline \multicolumn{7}{|l|}{ Included in meta-analysis [3] } \\
\hline Calverley, 2011 (INSPIRE) [10] & Fluticasone propionate & 1323 & 658 & 665 & 3 & 0 \\
\hline Crim, 2009 (TORCH) [11] & Fluticasone propionate & 6112 & 3067 & 3045 & 21 & 16 \\
\hline Dransfield, 2013 [12] & Fluticasone furoate & 3255 & 2437 & 818 & 8 & 0 \\
\hline Kardos, 2007 [13] & Fluticasone propionate & 792 & 408 & 384 & 1 & 1 \\
\hline SC040041 [14] & Fluticasone propionate & 186 & 92 & 94 & 2 & 1 \\
\hline Sharafkhaneh, 2012 [15] & Budesonide & 1218 & 815 & 403 & 1 & 0 \\
\hline Total & & 12886 & & & & \\
\hline \multicolumn{7}{|l|}{ Not included in meta-analysis } \\
\hline Ferguson, 2017 (RISE) [16] & Budesonide & 1219 & 606 & 613 & 0 & 0 \\
\hline Vestbo, 2016 (SUMMIT) [4] & Fluticasone furoate & 16485 & 8256 & 8229 & 0 & 0 \\
\hline Papi, 2018 (TRIBUTE) [5] & Beclometasone & 1532 & 764 & 768 & 0 & 0 \\
\hline Vestbo, 2017 (TRINITY) [17] & Beclometasone & 2691 & 1616 & 1705 & 0 & 0 \\
\hline Lipson, 2018 (IMPACT) [18] & Fluticasone furoate & 10355 & 8285 & 2070 & 19 & 9 \\
\hline Ferguson, 2018 (KRONOS) [6] & Budesonide & 1896 & 1271 & 625 & 1 & 0 \\
\hline Siler, 2017 [19] & Fluticasone furoate & 1620 & 806 & 814 & 0 & 0 \\
\hline Wedzicha, 2016 (FLAME) [20] & Fluticasone propionate & 3362 & 1682 & 1680 & 2 & 6 \\
\hline Zongh, 2015 (LANTERN) [21] & Fluticasone propionate & 741 & 369 & 372 & 0 & 0 \\
\hline Vogelmeier, 2013 (ILLUMINATE) [22] & Fluticasone propionate & 523 & 264 & 259 & 0 & 0 \\
\hline Total & & 40424 & 31396 & 22544 & 58 & 33 \\
\hline
\end{tabular}

cases were reported. We performed a joint analysis of the RCTs included in the meta-analysis of FESTIC et al. [3] and those published subsequently with a total of 53940 patients (31396 ICS and 22544 non-ICS). In this analysis, mortality from pneumonia was 58/31396 for ICS users and 33/22544 for non-ICS. (RR 0.97, 95\% CI $0.58-1.60 ; \mathrm{p}=0.89, \mathrm{I}^{2}=7.8 \%$ ). We believe that these data reinforce the notion that pneumonia-related deaths are very infrequent in RCTs and, given the number of patients included, the clinical relevance of ICS in pneumonia mortality is doubtful.

Certainly, pneumonia is an undesirable event, but the increased risk of pneumonia in COPD patients should be counter-balanced by a decrease in exacerbations, especially the most severe that require hospitalisation, and that lead to an increase in mortality, as SuISSA et al. [23] have previously demonstrated.

Therefore, we believe that the conclusion stated by SUISSA [1] that: "the evidence is now clear that ICS use is associated with a higher incidence of pneumonia and of pneumonia-related mortality", is debatable, given available data. The use of ICS should be in accordance with current recommendations, and clinicians must balance the pneumonia risk with the reduction in both severe exacerbations and the mortality.

Pere Almagro $\oplus^{1}$, Pablo Martinez-Camblor ${ }^{2}$ and Joan B. Soriano $\oplus^{3,4}$

${ }^{1}$ Multimorbidity Patients Unit, Internal Medicine Dept, University Hospital Mutua de Terrassa, University of Barcelona, Barcelona, Spain. ${ }^{2}$ Geisel School of Medicine at Dartmouth, Hanover, NH, USA. ${ }^{3}$ Hospital Universitario de la Princesa (IISP), Universidad Autónoma de Madrid, Madrid, Spain. ${ }^{4}$ Centro de Investigación Biomédica en Red de Enfermedades Respiratorias, CIBERES, Instituto de Salud Carlos III, Madrid, España.

Correspondence: Pere Almagro, Multimorbidity Patients Unit, Internal Medicine Dept, University Hospital Mutua de Terrassa, Pza. Dr Robert, 5, 08221, Terrassa, Barcelona, Spain. E-mail: 19908pam@comb.cat

Received: 11 April 2019| Accepted after revision: 30 May 2019

Conflict of interest: P. Almagro reports grants from AstraZeneca and SEPAR, personal fees from Chiesi, Boehringer Ingelheim and GlaxoSmithKline, travel support from Rovi and Esteve, outside the submitted work. P. Martinez-Camblor has nothing to disclose. J.B. Soriano reports grants from Linde, travel support from Almirall, AstraZeneca, Boehringer Ingelheim, Chest, Chiesi, ERS, Gebro, Grifols, GSK, Lipopharma, Mundipharma, Novartis, Pfizer, RiRL, Rovi, Sandoz, SEPAR and Takeda, outside the submitted work.

\section{References}

1 Suissa S. Inhaled corticosteroids preventing pneumonia mortality: paradox or selection bias? Eur Respir J 2019; 53: 1802112.

2 Soriano JB, Visick GT, Muellerova H, et al. Patterns of comorbidities in newly diagnosed COPD and as explained in the study and asthma in primary care. Chest 2005; 128: 2099-2107. 
3 Festic E, Bansal V, Gupta E, et al. Association of inhaled corticosteroids with incident pneumonia and mortality in COPD patients: systematic review and meta-analysis. COPD 2016; 13: 312-326.

4 Vestbo J, Anderson JA, Brook RD, et al. Fluticasone furoate and vilanterol and survival in chronic obstructive pulmonary disease with heightened cardiovascular risk (SUMMIT): a double-blind randomised controlled trial. Lancet 2016; 387: 1817-1826.

5 Papi A, Vestbo J, Fabbri L, et al. Extrafine inhaled triple therapy versus dual bronchodilator therapy in chronic obstructive pulmonary disease (TRIBUTE): a double-blind, parallel group, randomised controlled trial. Lancet 2018; 391: 1076-1084.

6 Ferguson GT, Rabe KF, Martinez FJ, et al. Triple therapy with budesonide/glycopyrrolate/formoterol fumarate with co-suspension delivery technology versus dual therapies in chronic obstructive pulmonary disease (KRONOS): a double-blind, parallel-group, multicentre, phase 3 randomised controlled trial. Lancet Respir Med 2018; 10: 747-758.

7 Joo MJ, Au DH, Fitzgibbon ML, et al. Inhaled corticosteroids and risk of pneumonia in newly diagnosed COPD. Respir Med 2010; 104: 246-252.

8 Suissa S, Patenaude V, Lapi F, et al. Inhaled corticosteroids in COPD and the risk of serious pneumonia. Thorax 2013; 68: 1029-1036.

9 Suissa S, Dell'Aniello S, Ernst P. Comparative effectiveness and safety of LABA-LAMA vs LABA-ICS treatment of COPD in real-world clinical practice. Chest 2019; 155: 1158-1165.

10 Calverley PMA, Stockley RA, Seemungal TAR, et al. Reported pneumonia in patients with COPD: findings from the INSPIRE study. Chest 2011; 139: 505-512.

11 Crim C, Calverley PM, Anderson JA, et al. Pneumonia risk in COPD patients receiving inhaled corticosteroids alone or in combination: TORCH study results. Eur Respir J 2009; 34: 641-647.

12 Dransfield MT, Bourbeau J, Jones PW, et al. Once-daily inhaled fluticasone furoate and vilanterol versus vilanterol only for prevention of exacerbations of COPD: two replicate double-blind, parallel-group, randomised controlled trials. Lancet Respir Med 2013; 1: 210-223.

13 Kardos $\mathrm{P}$, Wencker $\mathrm{M}$, Glaab $\mathrm{T}$, et al. Impact of salmeterol/fluticasone propionate versus salmeterol on exacerbations in severe chronic obstructive pulmonary disease. Am J Respir Crit Care Med 2007; 175: 144-149.

14 GlaxoSmithKline. A Randomized, Double-Blind, Parallel-Group Clinical Trial Evaluating the Effect of the Fluticasone Propionate/Salmeterol Combination Product 250/50mcg Twice Daily Via DISKUS ${ }^{\circ}$ Inhaler Versus Salmeterol 50mcg Twice Daily Via DISKUS ${ }^{\circledast}$ Inhaler on Bone Mineral Density in Subjects With Chronic Obstructive Pulmonary Disease (COPD). https://clinicaltrials.gov/ct2/show/NCT00355342 Date last updated: 2 July 2019.

15 Sharafkhaneh A, Southard JG, Goldman M, et al. Effect of budesonide/formoterol pMDI on COPD exacerbations: a double-blind, randomized study. Respir Med 2012; 106: 257-268.

16 Ferguson GT, Tashkin DP, Skärby T, et al. Effect of budesonide/formoterol pressurized metered-dose inhaler on exacerbations versus formoterol in chronic obstructive pulmonary disease: the 6-month, randomized RISE (Revealing the Impact of Symbicort in reducing Exacerbations in COPD) study. Respir Med 2017; 132: 31-41.

17 Vestbo J, Papi A, Corradi M, et al. Single inhaler extrafine triple therapy versus long-acting muscarinic antagonist therapy for chronic obstructive pulmonary disease (TRINITY): a double-blind, parallel group, randomised controlled trial. Lancet 2017; 389: 1919-1929.

18 Lipson DA, Barnhart F, Brealey N, et al. Once-daily single-inhaler triple versus dual therapy in patients with COPD. N Engl J Med 2018; 378: 1671-1680.

19 Siler TM, Nagai A, Scott-Wilson CA, et al. A randomised, phase III trial of once-daily fluticasone furoate/ vilanterol 100/25 $\mu \mathrm{g}$ versus once-daily vilanterol $25 \mu \mathrm{g}$ to evaluate the contribution on lung function of fluticasone furoate in the combination in patients with COPD. Respir Med 2017; 123: 8-17.

20 Wedzicha JA, Banerji D, Chapman KR, et al. Indacaterol-glycopyrronium versus salmeterol-fluticasone for COPD. N Engl J Med 2016; 374: 2222-2234.

21 Zhong N, Wang C, Zhou X, et al. LANTERN: a randomized study of QVA149 versus salmeterol/fluticasone combination in patients with COPD. Int J Chron Obstrut Pulmon Dis 2015; 10: 1015-1026.

22 Vogelmeier CF, Bateman ED, Pallante J, et al. Efficacy and safety of once-daily QVA149 compared with twice-daily salmeterol-fluticasone in patients with chronic obstructive pulmonary disease (ILLUMINATE): a randomised, double-blind, parallel group study. Lancet Respir Med 2013; 1: 51-60.

23 Suissa S, Dell'Aniello S, Ernst P. Long-term natural history of chronic obstructive pulmonary disease: severe exacerbations and mortality. Thorax 2012; 67: 957-963.

Copyright @ERS 2019

From the authors:

I thank P. Almagro and co-workers for their letter, which provides updated data regarding the association between inhaled corticosteroids (ICS) and pneumonia mortality in chronic obstructive pulmonary disease (COPD). It confirms the shortage of, and need for, rigorous studies on this question. My article, on the other hand, was focusing on a methodological, causal inference explanation for the paradoxical phenomenon of

@ERSpublications

The "paradoxical" effect of inhaled corticosteroids increasing pneumonia incidence in COPD but reducing post-pneumonia and all-cause mortality is no paradox but due to selection and immortal time biases in the observational studies of mortality http://bit.ly/2Yd3hDh

Cite this article as: Suissa S. Inhaled corticosteroids and pneumonia mortality in COPD patients. Eur Respir J 2019; 54: 1901276 [https://doi.org/10.1183/13993003.01276-2019]. 
observational studies reporting that ICS use increases the incidence of pneumonia in contrast with other observational studies reporting that ICS use prior to a pneumonia event decreases mortality [1].

Nevertheless, their conclusion that in using ICS in COPD "clinicians must balance the pneumonia risk with the reduction in both severe exacerbations and the mortality" is not founded on the evidence available to date. This conclusion implies that while ICS increase the risk of pneumonia, they are also effective at reducing the incidence of both severe exacerbations and mortality. The latter is not supported by the totality of evidence. Indeed, a network meta-analysis of 99 randomised controlled trials shows that ICS do not reduce the incidence of severe exacerbations in COPD, on the contrary they appear to increase it, when compared with mono or dual bronchodilators [2]. This meta-analysis also corroborates the increased risk of pneumonia with ICS [2]. With respect to mortality, only observational studies reported a reduction in all-cause death with ICS $[3,4]$. However, these studies were shown to be seriously affected by immortal time bias, which tends to exaggerate a drug's beneficial effect $[5,6]$. Observational studies that were designed to avoid this bias showed no reduction in mortality [7]. To date, no randomised trial has shown that ICS are associated with a reduction in mortality $[2,8]$.

Therefore, the evidence-based balance that clinicians should be concerned with when prescribing ICS versus long-acting bronchodilators in patients with COPD is between the risk of pneumonia and perhaps a reduction of mild and moderate exacerbations, but certainly not the severe ones or mortality, as suggested by P. Almagro and co-workers.

The more recent observational studies conducted in real-world clinical practice settings suggest that ICS may be effective at reducing moderate exacerbations only in the subset of patients with significant eosinophilia or frequent exacerbators $[9,10]$. Consequently, with the established risk of pneumonia with ICS, this therapy should only be used sparingly in the subset of COPD patients for whom the benefit may outweigh the risk, such as patients with asthma, frequent exacerbators and those with significant eosinophilia [11, 12]. More research is needed to better identify such markers for a more accurate precision medicine approach to the treatment of COPD patients [13].

\section{Samy Suissa}

Center for Clinical Epidemiology, Lady Davis Institute, Jewish General Hospital, and the Depts of Epidemiology and Biostatistics and of Medicine, McGill University, Montreal, QC, Canada.

Correspondence: Samy Suissa, Centre for Clinical Epidemiology, Jewish General Hospital, 3755 Cote Ste-Catherine, Montreal, QC, Canada H3T 1E2. E-mail: samy.suissa@mcgill.ca

Received: 26 June 2019 | Accepted after revision: 27 June 2019

Conflict of interest: S. Suissa reports personal fees for board membership from Novartis and Boehringer Ingelheim, grants from Boehringer Ingelheim/Pfizer, personal fees for lectures from AstraZeneca, outside the submitted work.

\section{References}

1 Suissa S. Inhaled corticosteroids preventing pneumonia mortality: paradox or selection bias? Eur Respir J 2019; 53: 1802112 .

2 Oba Y, Keeney E, Ghatehorde N, et al. Dual combination therapy versus long-acting bronchodilators alone for chronic obstructive pulmonary disease (COPD): a systematic review and network meta-analysis. Cochrane Database Syst Rev 2018; 12: CD012620.

3 Sin DD, Tu JV. Inhaled corticosteroids and the risk of mortality and readmission in elderly patients with chronic obstructive pulmonary disease. Am J Respir Crit Care Med 2001; 164: 580-584.

4 Soriano JB, Vestbo J, Pride NB, et al. Survival in COPD patients after regular use of fluticasone propionate and salmeterol in general practice. Eur Respir J 2002; 20: 819-825.

5 Suissa S. Effectiveness of inhaled corticosteroids in chronic obstructive pulmonary disease: immortal time bias in observational studies. Am J Respir Crit Care Med 2003; 168: 49-53.

6 Suissa S. Inhaled steroids and mortality in COPD: bias from unaccounted immortal time. Eur Respir J 2004; 23 391-395.

7 Suissa S, Ernst P. Observational studies of inhaled corticosteroid effectiveness in COPD: lessons learned. Chest 2018; 154: 257-265.

8 Ernst P, Saad N, Suissa S. Inhaled corticosteroids in COPD: the clinical evidence. Eur Respir J 2015; 45: 525-537.

9 Suissa S, Dell'Aniello S, Ernst P. Comparative effectiveness of LABA-ICS versus LAMA as initial treatment in COPD targeted by blood eosinophils: a population-based cohort study. Lancet Respir Med 2018; 6: 855-862.

10 Suissa S, Dell'Aniello S, Ernst P. Comparative effectiveness and safety of LABA-LAMA vs LABA-ICS treatment of COPD in real-world clinical practice. Chest 2019; 155: 1158-1165.

11 Suissa S, Ariel A. Triple therapy in COPD: only for the right patient. Eur Respir J 2019; 53: 1900394.

12 Suissa S, Ernst P. Precision medicine urgency: the case of inhaled corticosteroids in COPD. Chest 2017; 152: $227-231$

13 Suissa S, Ariel A. Triple therapy trials in COPD: a precision medicine opportunity. Eur Respir J 2018; 52: 1801848. 